\title{
Identification of Gene Expression Changes Associated with the Progression of Retinal Degeneration in the rd1 Mouse
}

\author{
Abigail S. Hackam, ${ }^{1,2}$ Richelle Strom ${ }^{3}$ Dongmei Liu,${ }^{4}$ Jiang Qian, ${ }^{1}$ Chenwei Wang, ${ }^{1}$ \\ Deborab Otteson, ${ }^{1}$ Tushara Gunatilaka, ${ }^{1}$ Ronald H. Farkas, ${ }^{1}$ Itay Chowers, ${ }^{1}$ \\ Masaaki Kageyama, ${ }^{5}$ Thierry Leveillard, ${ }^{6}$ Jose-Alain Sabel, ${ }^{6}$ Peter A. Campochiaro, ${ }^{1,7}$ \\ Giovanni Parmigiani, ${ }^{4,8,9}$ and Donald J. Zack ${ }^{1,7,10,11}$
}

Purpose. One approach to gaining insight into the biological pathways contributing to rod and cone photoreceptor death is to identify patterns of gene expression changes. In the present study, a custom retinal microarray was developed to analyze the $r d 1$ mouse, a well-characterized animal model of human retinal degeneration.

Methods. A microarray was constructed containing cDNA fragments corresponding to genes known or postulated to be involved in normal retinal function, development, and disease. Gene expression in $r d 1$ retina was compared with agematched control retinas at three time points: the peak of rod degeneration (postnatal day [P]14), early in cone degeneration (P35), and during cone degeneration (P50). Selected microarray results were confirmed with real-time PCR. The cellular

From the ${ }^{1}$ Guerrieri Center for Genetic Engineering and Molecular Ophthalmology at the Wilmer Eye Institute; the ${ }^{3}$ Department of Ophthalmology, Wilmer Eye Institute; Departments of ${ }^{4}$ Biostatistics, ${ }^{8}$ Oncology, ${ }^{9}$ Pathology, ${ }^{10}$ Molecular Biology and Genetics, ${ }^{7}$ Neuroscience and the ${ }^{11}$ McKusick-Nathans Institute of Genetic Medicine, Johns Hopkins University School of Medicine, Baltimore, Maryland; ${ }^{5}$ Santen Pharmaceutical, Takayama, Japan; and ${ }^{6}$ Hôpital Saint-Antoine, Paris, France.

${ }^{2}$ Present affiliation: Bascom Palmer Eye Institute, University of Miami, School of Medicine, Miami, Florida.

Supported by grants from the National Eye Institute, Macula Vision Foundation, and Santen Pharmaceutical Co., Ltd., and by generous gifts from Mr. and Mrs. Marshall and Stevie Wishnack and from Mr. and Mrs. Robert and Clarice Smith. ASH is supported by a Canadian Institutes of Health Research Senior Research Fellowship. PAC is the George S. and Dolores Dore Eccles Professor of Ophthalmology and Neuroscience; DJZ is the Guerrieri Professor of Genetic Engineering and Molecular Ophthalmology and is a recipient of the Senior Investigator Award from Research to Prevent Blindness, Inc. Funding for the study was provided by Santen Pharmaceutical Co., Ltd. Under a licensing agreement between Santen Pharmaceutical and The Johns Hopkins University, ASH, DJZ, IC, MK, and RHF are entitled to a share of royalties received by the university on sales of products described in the article. The terms of this arrangement are managed by The Johns Hopkins University in accordance with its conflict of interest policies.

Submitted for publication October 27, 2003; revised March 26 and April 19, 2004; accepted April 21, 2004.

Disclosure: A.S. Hackam, (P); R. Strom, None; D. Liu, None; J. Qian, None; C. Wang, None; D. Otteson, None; T. Gunatilaka, None; R.H. Farkas, None; I. Chowers, (P); M. Kageyama, Santen Pharmaceutical (E, P); T. Leveillard, None; J.-A. Sahel, None; P.A. Campochiaro, None; G. Parmigiani, None; D.J. Zack, Santen Pharmaceutical (F, P)

The publication costs of this article were defrayed in part by page charge payment. This article must therefore be marked "advertisement" in accordance with 18 U.S.C. $\$ 1734$ solely to indicate this fact.

Corresponding author: Donald J. Zack, 809 Maumenee Building, The Johns Hopkins University School of Medicine, 600 N. Wolfe Street, Baltimore, MD 21287; dzack@bs.jhmi.edu. distribution of one of the differentially expressed genes, dickkopf 3 (Dkk3), was assessed by in situ hybridization.

RESULTs. At each stage of degeneration, there was only limited overlap of the genes that showed increased expression, suggesting the involvement of temporally distinct molecular pathways. Genes active in transport mechanisms and in signaling pathways were differentially expressed during rod degeneration, whereas genes with functions in protein modification and cellular metabolism were differentially expressed during cone degeneration. Increased expression of genes involved in cell proliferation pathways and oxidative stress was observed at each time point.

Conclusions. These microarray results provide clues to understanding the molecular pathways underlying photoreceptor degeneration and indicate directions for future studies. In addition, comparisons of normal and degenerated retina identified numerous genes and ESTs that are potentially enriched in rod photoreceptors. (Invest Ophthalmol Vis Sci. 2004;45: 2929-2942) DOI:10.1167/iovs.03-1184

$\mathrm{T}$ he molecular events that contribute to retinal degeneration 1 are highly complex, reflecting in part the interdependence of different retinal cell types and the intimate functional and structural contacts between photoreceptors and the adjacent retinal pigment epithelium. Mutations in more than 80 genes, mostly expressed in rod photoreceptors, have been implicated in retinal degenerations, and more than 50 additional disease loci have been mapped (RetNet, http://www.sph.uth.tmc.edu/ Retnet/home.htm; provided in the public domain by the University of Texas Houston Health Science Center, Houston, TX). Many of the disease-causing genes have been identified as key players in retinal activities, including enzymes involved in phototransduction and the visual cycle, transcription factors that control retina-specific gene expression, and structural proteins that support the unique outer segment structure of photoreceptors. ${ }^{1-3}$ Despite knowledge of the functions of many of these proteins, the cellular and molecular pathways leading from the primary mutation to cell death are not understood. An additional level of complexity exists for the pathogenesis of the more common retinal diseases, such as age-related macular degeneration (AMD) and glaucoma, which are believed to involve the interplay of multiple genetic and environmental factors.

Although loss of rods has substantial functional consequences such as night blindness and some constriction of visual fields, rod death by itself does not cause severe vision loss. Rather, it is the delayed wave of nonautonomous cone photoreceptor degeneration that results in blindness. The mechanism by which death of rods leads to death of cones is unknown. Several lines of evidence suggest that cone viability may depend on diffusible or contact-mediated factors, ${ }^{4-6}$ but it is not yet established whether their absence results in cone 
death. It has been proposed that these survival factors may be rod derived. ${ }^{7}$ Identification of gene expression changes that accompany cone degeneration is an important step toward distinguishing between these possibilities and generating new hypotheses.

Naturally occurring and experimentally generated rodent models have been valuable for exploring the histopathological, functional, and molecular changes that occur during retinal degeneration. ${ }^{8,9}$ One well-studied model is the retinal degeneration ( $r d 1)$ mutant mouse, which has a deficiency in the rod photoreceptor-specific cGMP phosphodiesterase $\beta$-subunit $(\beta \mathrm{PDE})$, a mutation that also causes retinal degeneration in humans. ${ }^{10}$ The phenotype of the $r d 1$ mutant allows one to address several questions applicable to many of the retinal dystrophies. For example, although early changes in cGMP and calcium dynamics ${ }^{11,12}$ can be directly attributed to the $\beta$ PDE mutation, the molecular events that lead to rod death and delayed cone degeneration are unclear. Recent data have described morphologic and molecular changes in inner retinal cells during and after photoreceptor degeneration in $r d 1$ and other models, ${ }^{13-15}$ yet the role of these cells in promoting or protecting photoreceptors from apoptosis is unknown. In addition, a variety of neurotrophic factors have been reported to reduce the rate of photoreceptor loss in $r d 1$ and other retinal degenerations (Refs. 16, 17 and references therein). Although Müller cells and microglia have been implicated in this process, ${ }^{18-20}$ the molecular mechanisms involved remain to be established.

Because rod and cone photoreceptor death and the reactive changes that occur in neighboring retinal cells are likely to involve the coordinated expression of multiple genes, one approach to identifying pathways involved, as well as individual disease-causing genes, is to monitor alterations in gene expression associated with degeneration. ${ }^{21,22}$ Among the methods being used to profile retinal gene expression, data mining of cDNA libraries ${ }^{23-25}$ and serial analysis of gene expression (SAGE) ${ }^{26}$ are well suited for in-depth quantitation of gene expression under a single experimental state. In comparison, microarray technologies have the advantage of being able to measure gene expression changes across multiple experimental conditions or different disease states. ${ }^{27-29}$ In a study of the $r d 1$ mouse utilizing a 588-gene cDNA macroarray, Jones et al. ${ }^{30}$ found increased expression of one gene, nucleoside diphosphate kinase nm23-M2, which is involved in transcriptional regulation and suppression of metastasis. ${ }^{30}$ With a 205 gene apoptosis-related macroarray, upregulation of frizzledrelated protein-2 (SFRP2) was detected in donor retinas from patients with retinitis pigmentosa, ${ }^{31}$ and subsequent experiments have provided additional data implicating involvement of the Wnt signaling pathway. ${ }^{32}$ Further demonstrating the power of these approaches, both $\mathrm{SAGE}^{33}$ and microarray analysis $^{34}$ have helped in the identification of inosine monophosphate dehydrogenase type 1 (IMPDH1) as the mutated gene in a form of autosomal dominant retinitis pigmentosa (RP1O).

In this study, we developed a custom mouse retinal cDNA microarray that includes genes that have predicted expression in retinal neurons and glia. We used the array to analyze gene expression in degenerating $r d 1$ retina and identified genes and molecular pathways that are potentially involved in rod photoreceptor death. Furthermore, by comparing a time series of degeneration, we identified gene expression changes that may mediate disease progression-in particular, the non-cell-autonomous death of cone photoreceptors. An additional finding was the identification of novel retina-enriched genes and expressed sequence tags (ESTs), several of which map to known human disease loci and can be considered as potential candidate genes for retinal diseases.

\section{Methods}

\section{Custom Retinal Array Preparation}

The mouse retinal microarray has been described in detail elsewhere. ${ }^{35}$ The cDNAs on the retinal array represent 5376 genes and were assembled from individually purchased IMAGE clones and from selected clones in a mouse eye cDNA library. The purchased clones were chosen by searching the Online Mendelian Inheritance in Man (OMIM), PubMed, and UniGene EST databases at the National Center for Biotechnology Information (NCBI; http://www.ncbi.nlm.nih.gov/; provided in the public domain by the National Institutes of Health, Bethesda, MD ${ }^{36}$ for all genes with known roles in normal retinal function, development, and degeneration and genes implicated in retinal diseases. To include genes that may not have been selected by these criteria, we also searched the UniGene database (NCBI; http:// www.ncbi.nlm.nih.gov/UniGene) for all murine ESTs that were expressed in retina and brain and that were obtainable. The selected IMAGE clones (3752 unique sequences) were purchased from Research Genetics (Huntsville, AL). An additional 1624 clones were obtained from a sequenced adult mouse eye cDNA library to increase the gene set, generously provided by Jeremy Nathans and Amir Rattner (The Johns Hopkins University). Functional annotation was performed with the Source and Go databases (http://genome-www5.stanford. edu/cgi-bin/source/sourceSearch and http://geneontology.org/), ${ }^{37,38}$ and manual annotation with NCBI PubMed (http://www.ncbi. nlm.nih.gov/PubMed/) and LocusLink databases (http://www.ncbi. nlm.nih.gov/LocusLink/), to confirm or provide missing annotations. Attempts to include the primary or major function of each gene were made. In some cases, more than one function was assigned.

The clones were rearrayed into 96-well plates, PCR amplified, purified, and eluted in TE. PCR-amplified clones were suspended in a final concentration of $50 \%$ dimethylsulfoxide (DMSO) and arrayed onto silylated slides (SuperAmine; Telechem, Sunnyvale, CA) using an arrayer (Microgrid II; Biorobotics, Cambridge, UK) with 100- $\mu$ m-tip quill pins (Biorobotics). The spots were printed in duplicate on the array, separated by half the length of the slide. Spot quality was verified by fluorescence staining (Sybr-Green II; Molecular Probes, Eugene, OR) on several slides from each print.

\section{RNA Isolation and Probe Labeling}

All procedures involving mice were performed in accordance with the ARVO Statement for the Use of Animals in Ophthalmic and Vision Research and were approved by the Animal Care and Use Committee at The Johns Hopkins University. Tissue samples were obtained from homozygous $r d 1 / r d 1$ mice on a C57BL/6 background (for postnatal day $[\mathrm{P}] 14$ and $\mathrm{P} 50),{ }^{39}$ or homozygous $r d 1 / r d 1$ mice on a $\mathrm{C} 3 \mathrm{H}$ background (for P35) and age-matched control C57BL/6 mice and were processed immediately or flash frozen and stored at $-80^{\circ} \mathrm{C}$. Retinas were dissected under a microscope to exclude pigmented epithelium and other extraretinal tissue. Total RNA was isolated using phenolchloroform extraction (TRIzol; Invitrogen, Carlsbad, CA). Retinas from four animals were pooled to account for the small amount of retinal tissue and low RNA yield per retina and also to minimize the effect of biological variability. A reference sample was made containing $30 \%$ retina RNA and $70 \%$ brain RNA, derived from a mix of strains at various ages, from juvenile to adult. RNA integrity was assessed by gel electrophoresis with $A_{260} / A_{280}$ absorbance ratios and by analyzing an aliquot (Bioanalyzer; Agilent, Palo Alto, CA).

\section{Microarray Hybridization}

Details of arraying and hybridization methodologies are included in the Supplemental Methods (available at www.iovs.org/cgi/content/full/ 45/9/2929/DC1) and were reported previously. ${ }^{35}$ Probe preparation and hybridization were based on published protocols. ${ }^{40,41} \mathrm{~A}$ minimum of four replicates were performed of each experiment, and dye swaps were used to minimize the potential for differential dye effects. The RNA used in replicate experiments for the mutant mice was from 
different preparations. A reference sample experimental design (wildtype versus reference and mutant versus reference) was used for time points P14 and P50, and a direct comparison design (wild-type versus mutant) was used at time point P35. This difference in comparison design was not predicted to affect the final results because each time point was analyzed separately to determine significant differential expression, and all subsequent clustering analyses were performed on the calculated mutant-wild-type ratios. Furthermore, we calculated the distribution of the expression ratios at each time point by dividing the ratios into groups that increased by $0.1 \log _{2}$ units. The distributions for the three time points were very similar, indicating that the microarray results from the two designs are highly comparable and that the mixed design did not introduce experimental bias (see the Results section and Fig. 2B).

Twenty micrograms of total RNA were labeled using an indirect dye-incorporation method with reverse transcriptase (SuperScript II; Invitrogen), random hexamers, and aminoallyl dUTP/dNTP (final concentrations: $1.25 \mathrm{mM}$ dATP, dCTP, and dGTP; $1 \mathrm{mM}$ dTTP; and 0.25 $\mathrm{mM}$ aminoallyl dUTP [Sigma-Aldrich, St. Louis, MO]). After removal of unincorporated nucleotides, the DNA was coupled to fluorescent dyes by incubation with monoreactive NHS-cy3 or -cy5 dye (Amersham Biosciences, Inc., Piscataway, NJ) for 2 hours at room temperature. The aminoallyl-labeled cDNA probes were hybridized to the printed slides in $50 \%$ formamide, $5 \times$ SSC and $0.1 \%$ SDS at $42{ }^{\circ} \mathrm{C}$ overnight in a vacuum-sealed hybridization chamber (GeneMachine, San Carlos, CA). Repetitive sequences were blocked with polyA DNA and $\mathrm{C}_{\mathrm{o}} \mathrm{t}$ fraction mouse DNA (Invitrogen). The hybridized arrays were washed at $42^{\circ} \mathrm{C}$ for 4 minutes in $1 \times$ SSC and $0.2 \%$ SDS, followed by two 4 -minute room-temperature washes, in $0.1 \times$ SSC and $0.2 \%$ SDS and then $0.1 \times$ SSC. The slides were dried with an air can and fluorescence images of the hybridized microarrays were generated by a scanner and its accompanying software (Scan Array 5000; Perkin Elmer, Boston, MA).

\section{Data Analysis}

Spot-finding, image analysis, and quantification were performed on the scanned microarray data TIFF files (Imagene software; Biodiscovery, Inc., Marina del Rey, CA). A linear combination method was applied to calculate the adjusted intensity measurements for arrays with multiple scans, as described in Chowers et al. ${ }^{41}$ Local background was subtracted from the spot signals, and the data were $\log _{2}$ transformed. Low-intensity spots were flagged and then treated by flooring to a threshold defined by the average intensity of all low-intensity spots within the same array. Flagged spots with intensity lower than the threshold were upgraded to the threshold, whereas spots with intensity higher than the threshold remained at the original values. This floor method maximized the proportion of informative spots included for later analysis, and at the same time minimized the effect of poorquality data arising from low-intensity signals. If a spot had both cy3 and cy 5 channels floored, it was not included in the normalization process, and the final $\log$ ratio of this spot was assigned as zero. For all other spots, we first did loess normalization based on multivariate analysis (MVA) plots. ${ }^{42}$ Plate effects and pin effects were checked for each array based on box plots. For arrays with a plate/pin effect, a median normalization was applied within each plate/pin, and the median log ratio was subtracted from the loess-normalized log ratio. Statistical analysis of the normalized and transformed data was performed with the Significance Analysis of Microarrays (SAM) program created by Tusher et al. ${ }^{43}$

An alternative clustering analysis was also developed because our experiments included a limited number of time points and experimental conditions. $T$ statistics were calculated between all successive time points as follows: Suppose there are $n$ time points in the experiment. First, $t$ statistics are calculated for the $n$ time points for each gene $i$ as

$$
t(i)=\frac{\bar{x}_{\mathrm{m}}(i)-\bar{x}_{\mathrm{w}}(i)}{\sqrt{\frac{V_{\mathrm{m}}(i)+V_{\mathrm{w}}(i)}{n_{1}+n_{2}-2}\left(1 / n_{1}+1 / n_{2}\right)}}
$$

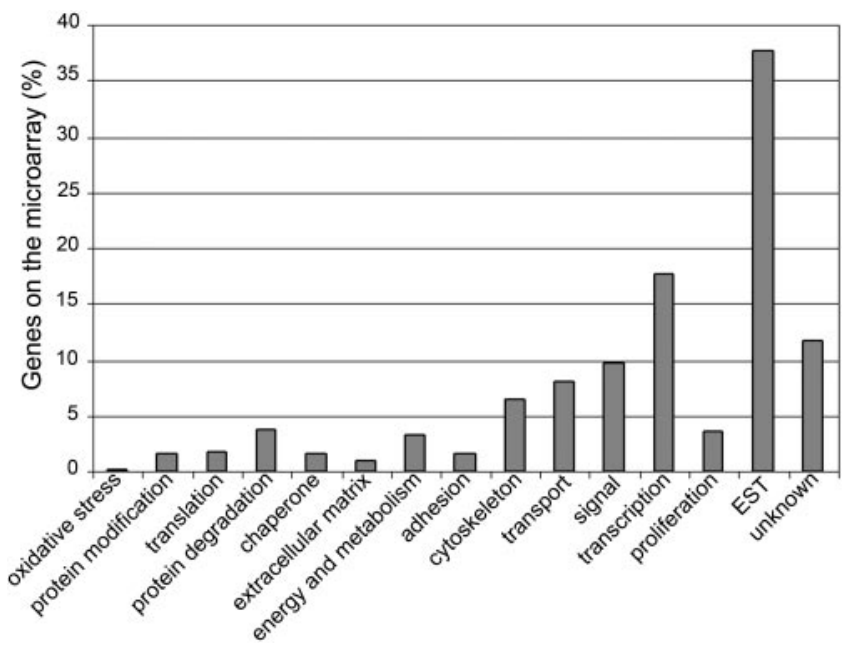

Figure 1. Functional annotation of genes on the mouse custom cDNA array. The percentage of genes in each functional class is shown, out of the total number of genes in the array.

where $\bar{x}_{m}$ and $\bar{x}_{\mathrm{w}}$ are the average expression ratios for mutant and wild-type, $V_{\mathrm{m}}$ and $V_{\mathrm{w}}$ are the within-group variances for mutant and wild-type, and $n_{1}$ and $n_{2}$ are the number of measurements for mutant and wild-type. Next, considering two successive time points, we defined expression changes of "up," "down," or "no change," by choosing a set of threshold values for the $t$ statistics. With combinations of different expression changes at each time step, all possible expression patterns can be constructed. For example, for an experiment with three time points, we would have eight different patterns ("up-up," "up-down," "no change-up," and so on). Permutation analysis was performed to evaluate the statistical significance for each pattern. For each expression pattern, we counted the numbers of genes that have satisfied the criteria for the pattern before and after the permutation, and the ratio between these two numbers was used as a conservative estimate of the false-discovery rate.

The statistical significance of the distribution of functional classes of the differentially expressed genes was determined as follows: If the differentially expressed genes tend to come from a particular functional group, the frequency of differentially expressed genes for this group would be significantly higher than its corresponding frequency in the total gene set on the array. Binomial and Pearson $\chi^{2}$ tests ${ }^{44}$ were performed to check whether the distribution of the percentage of differentially expressed genes that fall into various functional categories is different from the distribution of the percentage of all genes that fall into each functional group. When each functional group is considered separately, the number of genes that fall into a single group follows a binomial distribution. Based on the null distribution of genes in the functional classes (Fig. 1), we calculated the probability for the number of observed differentially expressed genes that fall into a functional group.

\section{Quantitative PCR}

Total RNA was extracted from retina tissue from a pooled sample of four animals, as described earlier. cDNA was synthesized from $1 \mu \mathrm{g}$ total RNA with reverse transcriptase (Thermoscript; Invitrogen). Quantitative real-time PCR (QPCR) was then performed (Lightcycler-FastStart DNA Master SYBR Green I kit; Roche Diagnostics, Nutley, NJ), according to the manufacturer's instructions. Each QPCR assay reaction also included amplification of the control genes actin or acidic ribosomal phosphoprotein $\mathrm{P}_{0}(A R P)^{45}$ from each cDNA reaction. Primers were chosen from exons separated by large introns, and the PCR reaction quality and specificity were verified by melting-curve dissociation analysis and gel electrophoresis of the amplified product. For quantification, a standard curve was generated from the cDNA tem- 
plate. Relative transcript levels of each gene were calculated using the second derivative maximum values from the linear regression of cycle number versus log concentration of the amplified gene. Amplification of the control genes was used for normalization. Primer sequences are included in the Supplemental Methods available online.

\section{In Situ Hybridization}

Probe preparation and hybridization of mouse dickkopf 3 was performed as previously described, with minor modification. ${ }^{46}$ The detailed protocol can be found in the Supplementary Methods.

\section{Results}

\section{Design and Optimization of the Microarray}

The mouse retinal custom array was designed to include genes that would be likely candidates for involvement in normal and disease processes in the retina. Genes were chosen based on function or tissue distribution. The first group included genes involved in essential cellular mechanisms, such as transcription and signaling; genes that had known activities in the retina, such as phototransduction and outer segment structural proteins; and genes implicated directly in disease by identified mutations, or indirectly, as part of general disease processes of neurodegeneration and retinopathies, such as apoptosis and angiogenesis. The genes were selected by searching literature and online database resources (NCBI, PubMed, OMIM; see the Methods section). In addition, we wanted to include all genes expressed in the retina, regardless of whether their function was known, by selecting all available mouse retina ESTs. Because a limited number of mouse retina libraries were in UniGene at the start of the project, we also selected available genes and ESTs expressed in the brain to have a large representation of neuronal and glial genes on the array. We also included 1624 clones from a sequenced adult mouse eye cDNA library (Jeremy Nathans and Amir Rattner, The Johns Hopkins University). In total, we obtained 5376 clones for the murine retina nonredundant gene set. The genes were annotated into the classes shown in Figure 1. Of note, more than one third of the genes in the set included ESTs, predicted genes, and genes of unknown function.

Various optimization and validation studies for probe labeling and hybridization were performed with the printed arrays. For example, in our experience, PCR products resuspended in $50 \%$ DMSO produced better spot morphologies and hybridization intensities than those in SSC-containing buffers $(3 \times$ SSC or $25 \% \mathrm{DMSO} / 3 \times \mathrm{SSC}$; data not shown). We also found that aminosilane-coated slides produced more consistent results than those that were polylysine-coated, and various aminoallyl UTPto-TTP ratios were tested to determine which gave the most favorable dye incorporation and signal-to-noise ratios. All subsequent analyses were performed with the optimized protocol described in the Methods section, which is similar to the protocol we recently reported for human retinal arrays. ${ }^{41}$

To assess microarray reliability, identical samples were compared using a self-self hybridization. Scatterplot analysis revealed a high degree of correlation, with an $R^{2}$ of 0.9619 (Fig. $2 \mathrm{~A})$. Only seven genes of the 10,752 spots on the slide $(0.065 \%$; each gene printed twice) showed a greater than twofold ratio of normalized cy5/cy3 values. As expected, low-intensity signals were more variable: All the genes that had spurious differential expression had intensity levels close to background. This test also demonstrated that there was minimal artifactual variation from dye effect.

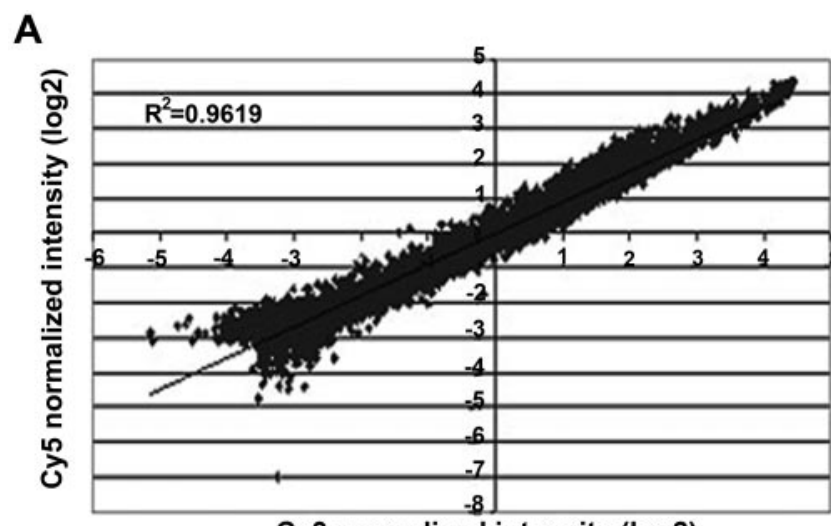

Cy3 normalized intensity (log2)

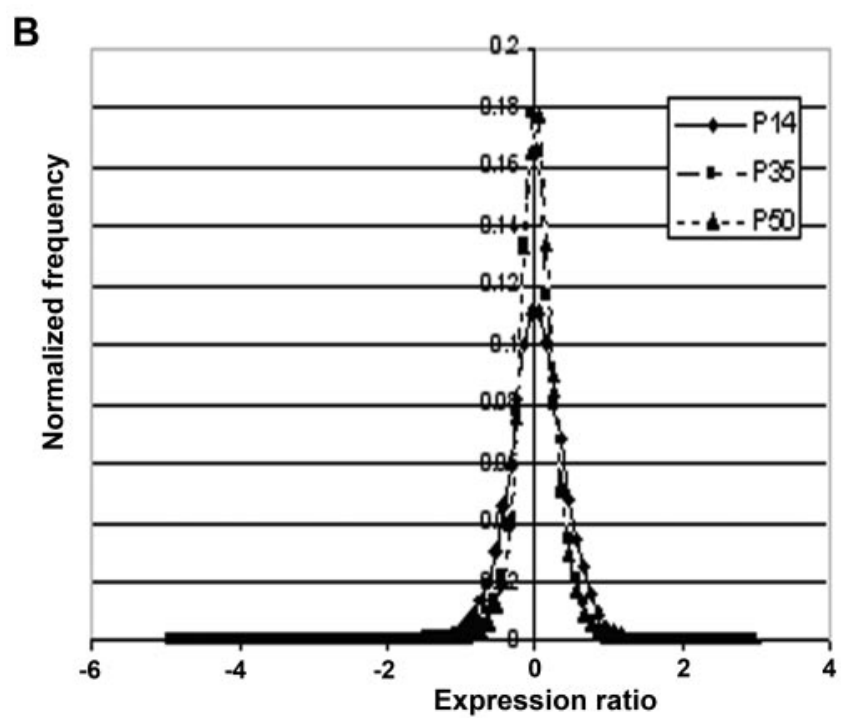

FigURE 2. Validation of microarray hybridization. (A) A reference sample was hybridized to itself in a dye-swap experiment, demonstrating that there was minimal artifactual variation due to dye bias. Normalized intensity values $\left(\log _{2}\right)$ are shown for cy 3 and cy5 scans for each gene on the array. The correlation coefficient $\left(R^{2}\right)$ is indicated. (B) Overlapping distribution of expression ratios at $\mathrm{P} 14, \mathrm{P} 35$, and $\mathrm{P} 50$. Expression ratios, in increasing $0.1 \log _{2}$ units, were plotted against normalized frequencies. The overall distributions of expression ratios were very similar at all three time points. The two later time points, P35 and P50, were essentially indistinguishable. The distribution at P14 was slightly wider than that at P35 and P50, indicating that at the P14 time point $r d 1$ and wild-type retinas are more different from each other than they are at the other two points.

\section{Identification of Genes Differentially Expressed during Retinal Degeneration}

A time-series experiment was performed to compare the gene expression profiles of normal and degenerating homozygous rd1 retinas. The time points analyzed (P14, corresponding to the peak of rod degeneration; P35, post-rod and early cone degeneration; and P50, during cone degeneration) were chosen in an effort to maximize the likelihood of identifying genes that promote progression of degeneration, particularly genes that contribute to cone photoreceptor death.

To determine whether experimental bias was introduced by the mixed experimental design used in this study (see the Methods section for the experimental design used) we calculated the distribution of the expression ratios of the three time points (P14, P35, and P50). The overall distributions of expres- 
sion ratios were very similar at each time point (Fig. 2B), indicating that the results from the pair-wise and reference designs are comparable and that there was no detectable introduced bias. The two later time points, P35 and P50, completely overlap, suggesting that the observed larger number of expression changes at P35 (described later) reflects true biological events and are not an artifact due to the study design.

The SAM algorithm ${ }^{43}$ was used to determine the likelihood that observed expression level changes reflect true expression level differences ("real" change) rather than artifacts due to chance (see the Methods section for the normalization and statistical protocols used). Instead of using a predefined $n$-fold ratio cutoff, a false-discovery rate (FDR) was calculated by considering the variability in experimental measurements and comparing the expression ratios from the microarrays with ratios calculated by randomly permuting the control and experimental groups. Gene expression changes were considered significantly different between wild-type and mutant if they were identified in the SAM analysis using a low FDR. We first established which genes were differentially expressed at each of the time points by using FDR levels in the same low range (high stringency: $1.2 \%$ for $\mathrm{P} 14,0.2 \%$ for $\mathrm{P} 35$, and $0.5 \%$ for $\mathrm{P} 50$ ). At P14, 70 genes were differentially expressed: 69 decreased and 1 increased. At P35, 177 genes were decreased and 33 were increased, and at P50, 144 genes were decreased and 62 were increased (Table 1 and Supplemental Table 1 at www.iovs. org/cgi/content/full/45/9/2929/DC1). Increasing the FDR for the P14 analysis to $16 \%$ resulted in a larger number of differentially expressed genes (118 decreased and 62 increased). We chose to use this FDR level to allow for comparable subsequent analyses and clustering of the three time points, realizing that a fraction of the identified genes would not represent truly differentially expressed genes.

\section{Confirmation of Differentially Expressed Genes}

QPCR was used as an independent method to verify a subset of our results and to assess the reliability of the microarray data. We tested 11 genes in mutant and wild-type retinas at all three time points (33 expression changes in total). The genes were chosen to assess a range of expression ratios, including genes that had high differential expression and those that were unchanged on the arrays. The results of the QPCR analysis are shown in Figure 3 (see also Supplemental Table 2 at www.iovs. org/cgi/content/full/45/9/2929/DC1). There was a high correlation between array and QPCR mutant/wild-type ratios for the 11 genes tested $\left(R^{2}=0.8736\right)$. The direction of expression differences for mutant versus wild-type was replicated by QPCR with only three exceptions in the 33 changes tested. Furthermore, the QPCR results confirmed the dynamic change in expression observed on the array across the three time points. The absolute ratios differed between QPCR and the array, a finding that has also been reported in other studies. ${ }^{4-49}$ Therefore, the replication of the temporal pattern of gene expression changes by QPCR suggests that the microarray results accurately reflect biological changes.

\section{Temporal Patterns of Differential Expression during Degeneration}

Functional group analysis in microarray experiments can help provide insight into the molecular pathways involved in the biological process under study. However, in interpreting such analyses, it is important to exercise caution, because the assignment of genes to particular functional classes can sometimes be difficult and subjective. Some genes have multiple functions, some genes have functions that are only incompletely defined, some functional groups can be overlapping, and our knowledge of gene function is continually changing.
With these caveats in mind, the genes on the murine retinal array were divided into functional classes (Fig. 4) using the approach described in the Methods section. This comparison illustrates the overrepresentation of certain gene classes at each time point compared with their frequency in the gene set, suggesting their functional importance (Fig. 4A, Table 1). Of note is the large representation of genes involved in signaling processes at P14 and P50 compared with the whole array, transport genes at $\mathrm{P} 14$ and $\mathrm{P} 35$, and metabolism genes at $\mathrm{P} 35$ and P50. Genes involved in oxidative stress were most prominent during degeneration at $\mathrm{P} 35(1.9 \%$ vs. $0.2 \%$ in the entire gene set). Further subdivision of the differentially expressed genes into groups with increased and decreased expression and comparison to the entire gene set confirmed these trends (Figs. 4B, 4C).

The resultant classification made evident some potentially interesting differences between the P14, P35, and P50 time points. For example, equivalent numbers of protein-modification genes had increased or decreased expression at both P14 and P35, whereas at P50 there were three times more genes involved in protein modification that had increased rather than decreased expression (Figs. 4B, 4C). Similarly, at P35 there were no signaling genes with increased expression but many with decreased expression, in contrast to the P14 and P50 time points, which had similar numbers of signaling genes with increased and decreased expression (Fig. 4B, 4C). Because modulation of a given pathway might be expected to involve gene expression changes in both directions (for example, inhibitors decreased and activators increased), these differences in the directions of expression change may provide clues to the underlying cellular changes occurring at each time point. To investigate this concept further, we compared the nature of the genes that were changed.

As expected, genes known to be differentially expressed in rod photoreceptors had decreased expression at each of the three time points. In contrast, there was little overlap in the identity of the genes with increased expression. Forty-three genes (of 62) that were upregulated at P50 were not upregulated at P14 (Fig. 4B, Table 1 and Supplemental Table 1). Therefore, the array results may help to distinguish rod degeneration from cone degeneration. For example, different intercellular signaling and protein-modification genes were upregulated during cone degeneration at P50 than during rod degeneration at P14. Several calcium-activated proteins were upregulated only at P50 (e.g., calpain, calmodulin). In contrast, genes involved in cellular transport were more highly represented during rod degeneration than during cone degeneration, particularly those involved in modulating ion transport and neuronal transmission, such as $L y 6$ and NMDA1 subunit zeta 1 . These data suggest the involvement of different molecular events in rod and cone death.

We also compared the annotation of the differentially expressed genes to the frequencies of the functional classes on the entire array (Fig. 4A). We performed binomial and Pearson $\chi^{2}$ tests to determine whether the distribution of the percentage of differentially expressed genes that fall into various functional categories is different from their distribution in the set of all genes on the array (see Fig. 1 and the Methods section). Several functional groups had $P<0.001$ (Fig. 4), indicating that they had significantly higher or lower representation than expected (we chose a conservative probability cutoff because multiple groups were being tested).

The large data set of gene expression changes was clustered into smaller groups to identify genes that were behaving similarly, to infer biological information from the gene expression data. Standard clustering methods, such as hierarchical clustering, self-organizing maps or k-means clustering, are based on the distances between pair-wise gene expression profiles (us- 
TABLE 1. Differential Expression at P14, P35 and P50 in rd1 Retinas

\begin{tabular}{|c|c|c|}
\hline Gene & Accession No. & Function \\
\hline \multicolumn{3}{|l|}{ Increased Expression } \\
\hline \multicolumn{3}{|l|}{ P14 } \\
\hline Sulfated glycoprotein 2 isoform 2 /clusterin & Mm.196344 & Cell death \\
\hline Crystallin beta A4 & Mm.40324 & Unknown function \\
\hline EST & Mm.27363 & EST \\
\hline Secreted phosphoprotein 1 & Mm.321 & Adhesion \\
\hline Selenoprotein $\mathrm{P}$ & Mm.22699 & Transport \\
\hline cDNA DKFZp586N1922/CLIP-170-related protein & AL117468 & Cytoskeleton \\
\hline Microtubule-associated protein 1A & M83196 & Signaling, structural \\
\hline Neural cell adhesion molecule & Mm.39188 & Adhesion \\
\hline Dickkopf homologue 3 & Mm.55143 & Wnt signaling inhibitor, putative tumor suppressor \\
\hline Glutathione $S$ transferase mu 1 & Mm.2011 & Oxidative stress, metabolism \\
\hline \multicolumn{3}{|l|}{ P35 } \\
\hline EST highly similar to tissue inhibitor metalloproteinase 2 & Mm.206505 & EST/enzyme inhibition, metabolism \\
\hline Vimentin & Mm.7 & Structural \\
\hline Transketolase & Mm.154387 & Metabolism \\
\hline Antioxidant protein 2 & Mm.6587 & Oxidative stress, structural \\
\hline Dickkopf homologue 3 & Mm.55143 & Wnt signaling inhibitor, putative tumor suppressor \\
\hline Solute carrier family 25 & Mm.298 & Transport \\
\hline Sulfated glycoprotein 2 isoform $2 /$ clusterin & Mm.196344 & Cell death \\
\hline EST similar to $H$. sapiens KIAA 1077 protein/sulfatase 1 & Mm.45563 & EST/metabolism \\
\hline EST highly similar to excitatory amino acid transporter & Mm.206394 & Transport \\
\hline Secreted acidic cysteine-rich glycoprotein & Mm.35439 & Cytoskeleton \\
\hline \multicolumn{3}{|l|}{ P50 } \\
\hline Membrane glycoprotein M6 & Mm.178672 & Development, proliferation \\
\hline Calmodulin & Mm.34246 & Signaling \\
\hline EST highly similar to zygin I (FEZ1) & Mm.5264 & EST/adhesion, development \\
\hline Sulfated glycoprotein 2 isoform $2 /$ clusterin & Mm.196344 & Cell death, protein modification \\
\hline Antioxidant protein 2 & Mm.6587 & Oxidative stress \\
\hline EST highly similar to chimerin & Mm.41190 & EST/signaling \\
\hline EST & Mm.226753 & EST \\
\hline Protein-L-isoaspartate O-methyltransferase 1 & Mm.258431 & Protein modification \\
\hline Profilin II & Mm.20399 & Structural \\
\hline Ras homologue gene family, member $\mathrm{J}$ & Mm.27467 & Signaling \\
\hline \multicolumn{3}{|l|}{ Decreased Expression } \\
\hline \multicolumn{3}{|l|}{ P14 } \\
\hline Retinal $\mathrm{S}$ antigen & Mm.1276 & Signaling, vision \\
\hline Retinitis pigmentosa 1 homologue & Mm.78749 & Signaling, vision \\
\hline Phosducin & Mm.1205 & Signaling, vision \\
\hline Neural retina leucine zipper & Mm.20422 & Transcription, vision \\
\hline Guanine nucleotide-binding protein, alpha transducing 1 & Mm.69061 & Signaling, vision \\
\hline Rhodopsin & Mm.2965 & Signaling, vision \\
\hline $\mathrm{X}$-linked juvenile retinoschisis protein & Mm.41982 & Adhesion, vision \\
\hline Guanine nucleotide-binding protein beta 1 & Mm.2344 & Signaling, vision \\
\hline Dopamine receptor 4 & Mm.41075 & Signaling \\
\hline Brain type fatty acid binding protein & AF237712 & Unknown function \\
\hline \multicolumn{3}{|l|}{ P35 } \\
\hline Guanine nucleotide-binding protein, alpha transducing 1 & Mm.69061 & Signaling, vision \\
\hline Aryl hydrocarbon interacting protein like 1 & Mm.4452 & Signaling, vision \\
\hline Guanine nucleotide-binding protein beta 1 & Mm.2344 & Signaling, vision \\
\hline Retinitis pigmentosa 1 homologue & Mm.78749 & Signaling, vision \\
\hline EST & Mm.1881 & EST \\
\hline Rhodopsin & Mm.2965 & Signaling \\
\hline Phosducin & Mm.1205 & Signaling, vision \\
\hline EST & Mm.29308 & EST \\
\hline Prominin 1 & Mm.6250 & Unknown function, vision \\
\hline Retinal $\mathrm{S}$ antigen & Mm.1276 & Signaling, vision \\
\hline \multicolumn{3}{|l|}{ P50 } \\
\hline Rhodopsin & Mm.2965 & Signaling, vision \\
\hline Guanine nucleotide-binding protein, alpha transducing 1 & Mm.69061 & Signaling, vision \\
\hline Heat shock protein $60 \mathrm{kDa}$ & Mm.1777 & Protein modified/heat shock \\
\hline RIRD-1 & BG296148 & EST \\
\hline EST weakly similar to CGI 45 protein & AF151803 & EST \\
\hline Retinal $\mathrm{S}$ antigen & Mm.1276 & Signaling, vision \\
\hline Aryl hydrocarbon interacting protein-like 1 & Mm.4452 & Signaling, vision \\
\hline Phosducin & Mm.1205 & Signaling, vision \\
\hline EST & Mm.271986 & EST \\
\hline EST & Mm.29308 & EST \\
\hline
\end{tabular}

The top 10 genes that were increased and decreased at each time point determined by SAM analysis are shown. Accession numbers and major function(s) of each gene are listed. 


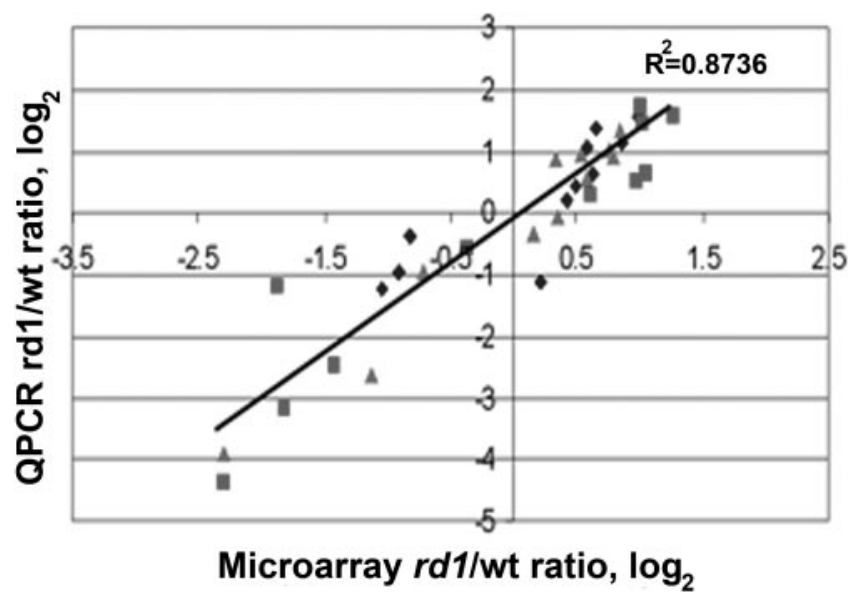

FiguRE 3. QPCR was used as an independent confirmation of the array results for 11 genes (RIRD1 [IMAGE clone 4505626], EST Mm.156168, vimentin, antioxidant protein 2, calcium channel CACNG4, cone-rod homeobox [crx], dickkopf homologue 3, tissue inhibitor of metalloproteinase 2 [TIMP2], Mm.34351, sparc/osteonectin, and Mm.41762). A scatterplot of microarray and QPCR for each gene at each time point shows a high correlation.

ing correlation coefficients). These methods are not optimal if only a few time points or experimental conditions are being compared, as was the case in this study. Therefore, a clustering method was developed that allowed us to determine genes that clustered based on a statistically significant threshold (see the Methods section).

The clustering analysis demonstrated that the temporal expression patterns varied among the genes, Some genes showed continuous increases, others decreased, and others had timepoint-specific expression changes. Because we were interested in the progression of cone degeneration, the genes were clustered based on the change in expression from P14 to P35 and from P35 to P50. Eight different clusters were identified based on the direction of gene expression changes between P35 and P14 and P50 and P35 (Fig. 5; gene lists of each cluster are available in Supplemental Table 3 at www.iovs.org/cgi/ content/full/45/9/2929/DC1). To assess the predictability of this clustering method, we determined which cluster contained known retinal genes. As expected, many of the genes that showed decreased expression at each time point, those in clusters 2 (down-down) and 6 (down-no change), are known retina-enriched genes. The largest number of genes was in cluster 4 (down-up), which contained genes with mutant/ wild-type expression ratios that dipped at P35, and in cluster 3, which had the opposite pattern (up-down), showing a mutant/wild-type ratio that peaked at P35. For example, the expression ratios for follistatin-like 2 , insulin-like growth factorbinding protein 7 , and several different crystallins peaked during early stages of cone degeneration (up-down), whereas the expression ratios for numerous genes involved in protein turnover, such as proteases, ubiquitin conjugating proteins, and chaperones, were higher during rod and cone degeneration and dipped at P35 (down-up). The coordinated expression changes may indicate that clustered genes participate in similar biological processes.

\section{Dickkopf 3 Localization in Degenerating Retina}

Genes with increased expression may be involved in contributing to or inhibiting apoptosis or may be involved in the extensive neural remodeling that occurs after photoreceptor degeneration. To begin to gain some insight into the functional role of the genes that are differentially expressed during de- generation in $r d 1$ mice, an important first step is to determine the cell types in which they are expressed in both the normal and degenerative retina.

We used in situ hybridization to examine the cellular expression pattern of one of the more interesting differentially expressed genes, dickkopf 3 (Dkk3). Dkk3 is a member of the dickkopf family of Wnt-signaling regulatory genes ${ }^{50}$ and has been implicated in the control of cell proliferation. ${ }^{51-53}$ Dkk3 has also been found in a recent study to inhibit Wnt signaling in PC12 cells, ${ }^{54}$ but does not appear to in other contexts. ${ }^{55-57}$ Expression of the Dkk3 gene has not been reported in degenerating retina, although the expression patterns of several dickkopf family members and Wnt-related genes have been described in the developing and adult normal eye. ${ }^{58,59}$ Therefore, we were interested in determining whether the cellular distribution of $D k k 3$ changes during retinal degeneration.

$D k k 3$ had a more than threefold higher expression in $r d 1$ animals at P35, compared with wild-type mice, and a twofold higher expression at P50. There was 1.6 fold higher expression at P14. Using in situ hybridization, we found that Dkk3 was expressed in inner nuclear layer and ganglion cell layer cells in normal and degenerating tissue (Fig. 6). The overall cellular distribution pattern did not change during degeneration.

\section{Identification and Chromosomal Localization of Novel Retina Genes}

A notable feature of our custom retinal array is the large proportion (over one third) of clones that represent undescribed, or novel, genes, including ESTs and hypothetical and predicted proteins. These clones are an important resource for identifying genes preferentially or specifically expressed in the mouse retina. As might be expected, we found that a significant fraction of the sequences showing decreased expression (16\%, 18\%, and $20 \%$ at P14, P35, and P50, respectively) corresponded to genes already known to be expressed in rod photoreceptors, and many of these have been identified as being mutated in various human hereditary retinal degenerations. Furthermore, many of the ESTs and novel genes were grouped in the down-down cluster along with several known photoreceptor-specific genes, implying that some of the unknown genes may also be expressed in photoreceptors. (It is also possible that some of the genes with decreased expression are expressed in cells in the inner nuclear layer and are differentially regulated during morphologic changes that occur in degenerating retina.) Many of the ESTs with reduced expression in rd1 mice at P35 and P50 may represent genes normally expressed in rod and cone photoreceptors, whereas ESTs with increased expression may represent genes expressed in nonphotoreceptor cells (which have a larger representation in rod-deficient retinas).

The clones on the array (known as well as novel genes) may facilitate the identification of genes that cause hereditary retinal diseases. To generate a list of candidate genes, we determined the chromosomal position of the human counterpart of the genes that had reduced expression in our analyses. As shown in Table 2, 42 of the mouse clones in the down-down and down-no change clusters had human homologues that mapped within chromosomal intervals implicated in retinal diseases (as defined by the RetNet database; known genes with causative mutations, and their corresponding chromosomal regions, were omitted). Despite the large size of some of these regions, the strategy of combining expression data with the chromosome position of the genes and with known retinal disease loci provides a powerful suggestion of a gene's involvement in disease. Curiously, most of the mapped genes are involved in neuronal signaling. Several novel genes were also localized to disease regions and will be interesting to explore further. 

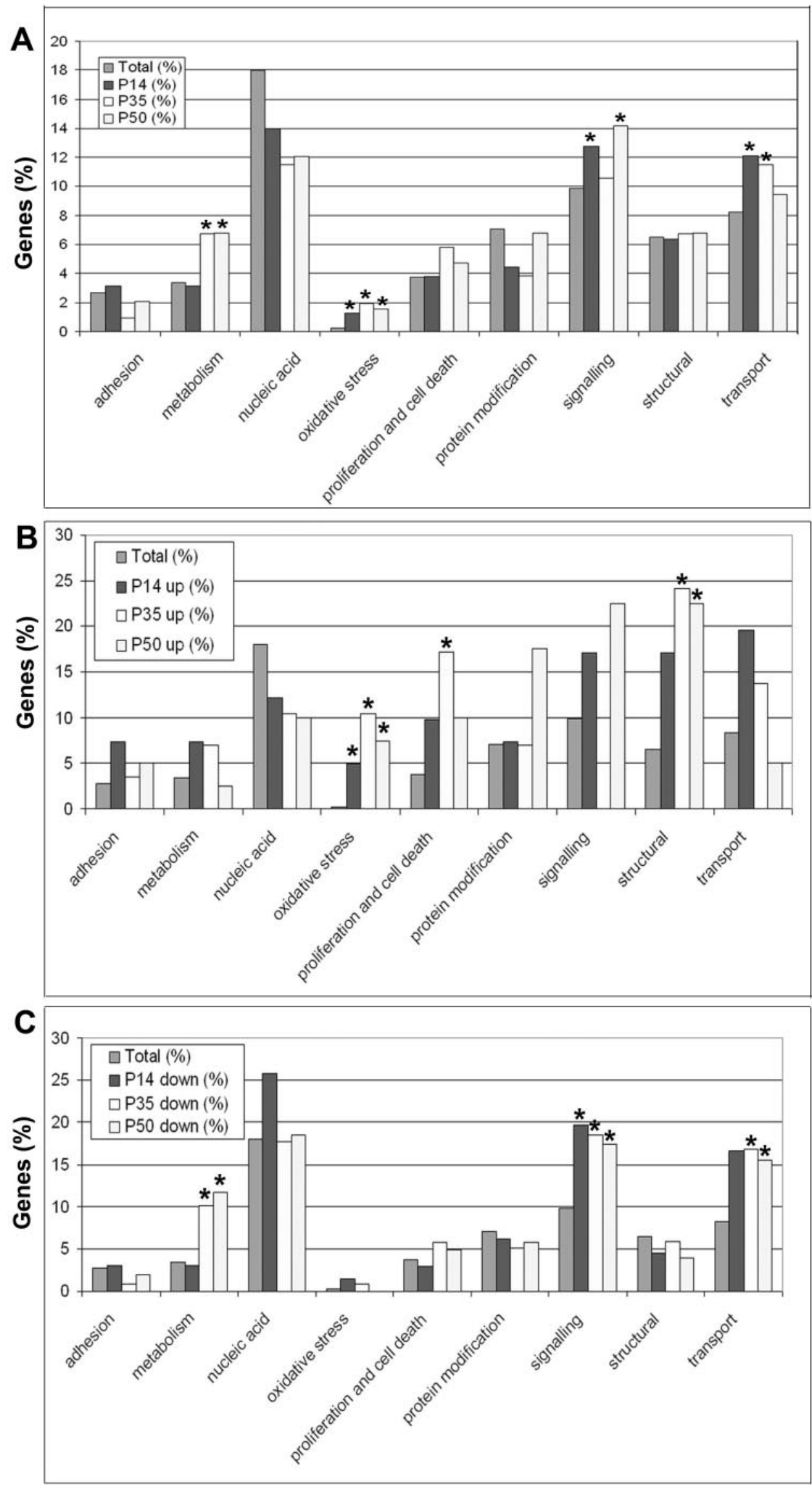

Functional class

FiguRe 4. Functional annotation of differentially expressed genes in $r d 1$ retinas during degeneration. (A) The percentage of differentially expressed genes in each functional class at each time point compared with the entire gene set (percentage of total). Based on the null distribution in Figure 1, the probability was calculated for the number of observed differentially expressed genes that fall into a functional group. A functional group with $P<0.001$ (*) $^{*}$ indicates that this group has significantly higher or lower frequency of genes than expected. (B, C) Percentage of genes with increased $(\mathbf{B})$ and decreased (C) expression in each functional class at each time point compared with the entire gene set (percent of total). A functional group with a $P<0.001\left(^{*}\right)$ indicates that this group has a significantly higher or lower frequency of genes than expected from the null distribution. 

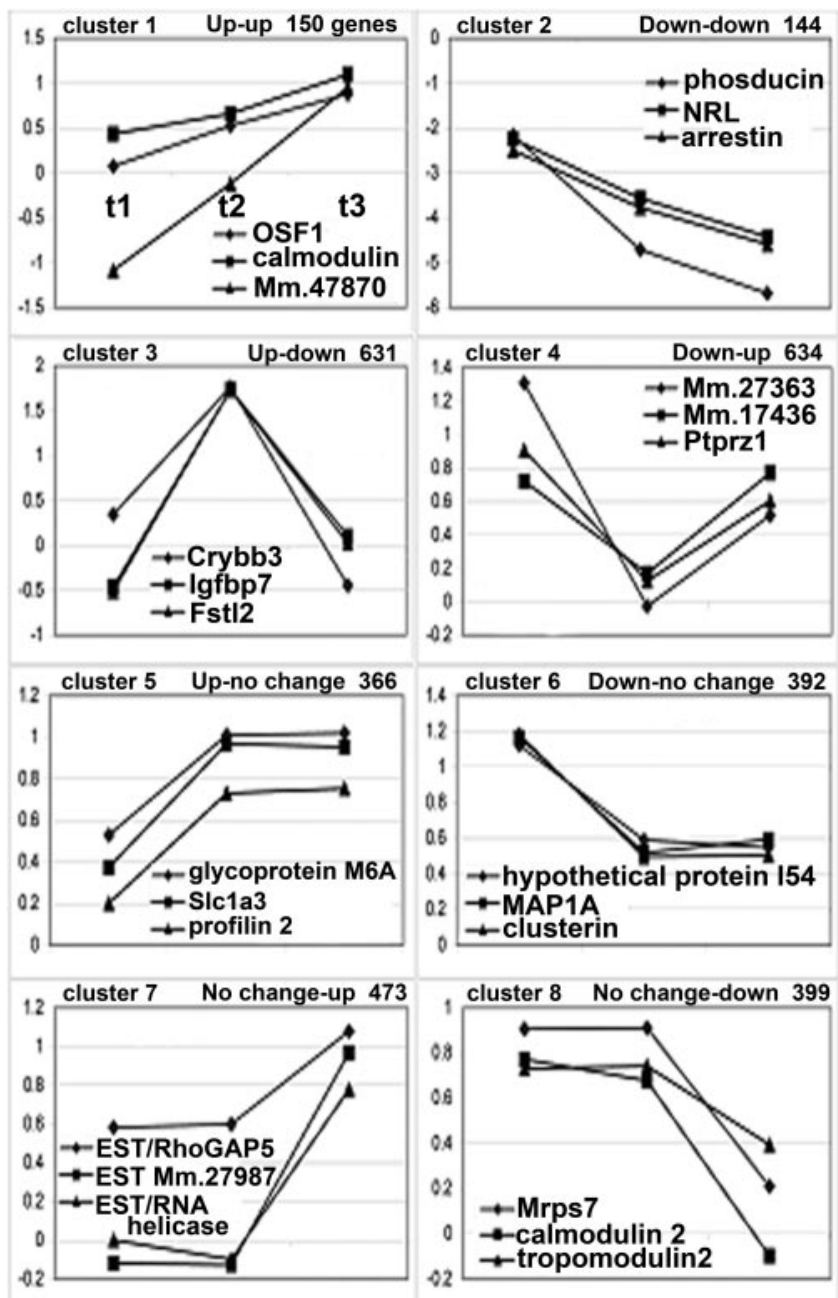

FIgURE 5. Clustering of genes into eight groups using $t$ statistics. Three genes in each cluster are shown to illustrate the pattern of expression changes. The vertical axis indicates the difference in mutant/wild-type expression ratios between time points P14 (t1), P35 $(\mathrm{t} 2)$, and $\mathrm{P} 50(\mathrm{t} 3)$. The total number of genes in the cluster is also shown in each graph.

\section{Discussion}

In retinitis pigmentosa and other retinal degenerations, mutations in genes predominantly expressed in rod photoreceptors often lead to rod degeneration followed by the death of cones. $^{60-62}$ To gain insight into the pathogenesis of these diseases, particularly the vision-robbing cone death, a custom mouse microarray was developed and used to characterize retinal gene expression in $r d 1$ mice at specific time points during degeneration. Despite the more rapid degeneration in this animal model compared with most human retinal diseases, $r d 1$ mice offer the benefit of investigating molecular mechanisms that originate from a defined primary mutation that correlates with a particular histologic pattern of cell death. Through this analysis, we have identified groups of genes that are candidate mediators of rod photoreceptor degeneration and may be involved in the initiation and progression of cone photoreceptor death. Future studies will include specific protein quantification of these candidate molecules to determine their significance to photoreceptor degeneration, a necessary step because RNA expression changes do not always reflect protein level changes.
We found particularly provocative the observation that several genes with products known to provide protection against oxidative damage, including antioxidant protein $2,{ }^{63}$ glutathione peroxidase $2,{ }^{64}$ and paraoxonase, ${ }^{65}$ were upregulated during the period of cone degeneration. This raises the question, could oxidative damage contribute to cone death after rods disappear? Rods and cones receive their oxygen supply from choroidal vessels that have very high flow and contain fenestrations that allow pooling of plasma, separated from the photoreceptors only by Bruch's membrane and the retinal pigmented epithelium. A high oxygen diffusion gradient allows adequate oxygenation through the entire outer nuclear layer. The elevated oxygen supply is balanced by extreme oxygen utilization by photoreceptors, which are packed with mitochondria to support the activity of the $\mathrm{Na} / \mathrm{K}$ pump required to maintain the dark current. As rods die, there is decreased oxygen demand, potentially resulting in excessive oxygen supply to the remaining cones. High levels of tissue oxygen increase oxidative stress, which can overwhelm protective mechanisms, as demonstrated by the observation that prolonged hyperoxia causes photoreceptor cell death. ${ }^{66,67}$ Thus, it seems reasonable to consider a possible contribution of oxidative damage to cone cell death.

Another interesting observation was that a group of genes usually associated with tissue growth and differentiation showed increased expression in rd1 retina during cone degeneration. Included among this group were the Wnt pathway gene dickkopf 3, membrane glycoprotein M6, insulin-like growth factor binding protein 5, and Bin-1 (also known as myc box dependent interacting protein 1 ). The products of these genes may act as part of signaling pathways that activate apoptosis, attempt to block apoptosis, or attempt to upregulate protective cell functions. For example, although dickkopf 3 activity in the retina has not been explored, it has been reported to be downregulated in lung carcinoma, ${ }^{51,52}$ suggesting that it may participate in the control of cellular proliferation. Increased expression of the Wnt-related genes SFRP and frizzled- 4 have been demonstrated in human retinal degenerations, ${ }^{31,32,68}$ and Wnt is known to regulate apoptosis in vitro. ${ }^{69,70}$ Membrane glycoprotein M6 is associated with calcium-mediated neuronal differentiation of PC12 cells, ${ }^{71}$ and insulin-like growth factor-binding proteins are known to mediate neuronal differentiation. ${ }^{72}$

Genes that had increased expression, particularly genes involved in growth and differentiation, could be part of the glial hypertrophy and proliferation that accompany photoreceptor degeneration. The role of retinal glia cells in cone photoreceptor degeneration in $r d 1$ mice is unclear, although during rod degeneration there are reports of increased glial fibrillary acidic protein (GFAP) ${ }^{73}$ and immediate-early genes in Müller cells. ${ }^{74}$ In our analysis, we found that vimentin, an intermediate filament protein associated with Müller cell hypertrophy $^{75}$ and apoptosis ${ }^{76}$ was increased at time points P35 and P50. Pleiotrophin, a gene that is found in glia in the brain and is involved in communication with neurons ${ }^{77}$ was increased at P50. Several immune-related genes had increased expression, such as the lymphocyte antigen 6 complex, consistent with activation of microglia, ${ }^{78}$ which have also been implicated in retinal degeneration. ${ }^{20}$

Müller cells are believed to have a protective effect on rod photoreceptors in several damage paradigms by providing neurotrophins, a well-described class of growth factors. ${ }^{18,19,79}$ It is plausible that glial reactive changes attempt to protect cones in $r d 1$, possibly through actions of the growth and differentiation genes that are differentially expressed. Detailed cell localization studies are necessary to demonstrate whether glia cells, and which type, express genes that we found upregulated on the array. 

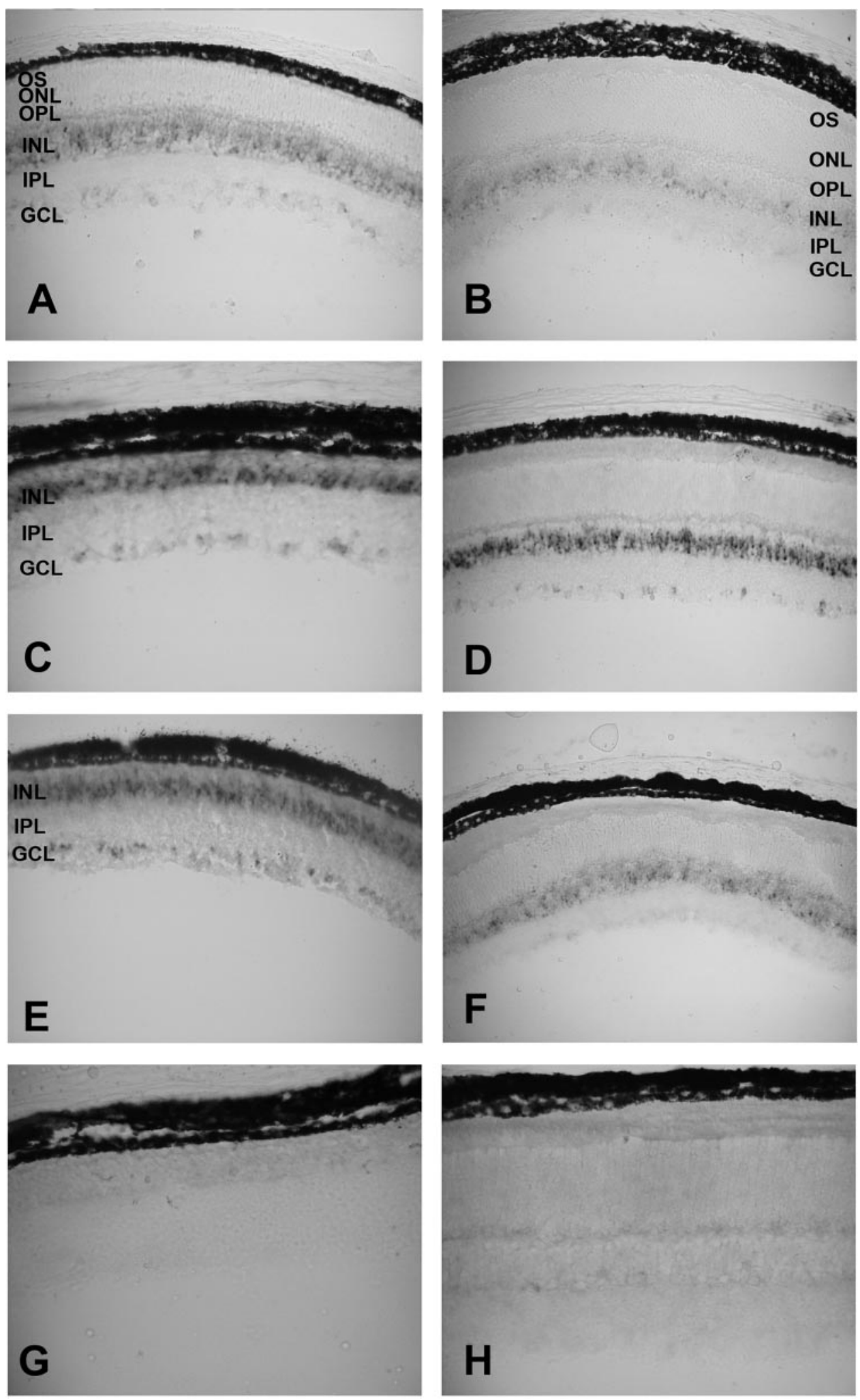

Figure 6. Distribution of retinal expression of dickkopf 3 (Dkk3) during degeneration. Microarray and QPCR demonstrated that expression of $D k k 3$ increased during degeneration. Sections of retina from $r d 1$ and control (C57BL/6) mice were hybridized to probes generated against the antisense strand of the mouse Dkk3 gene. $D k k 3$ is expressed in cells in the inner nuclear layer and ganglion cell layer; there was no obvious alteration in cellular distribution during degeneration. (A) P14 rd1, (B) P14 BL/6, (C) P35 rd1, (D) P35 BL/6, (E) $\mathrm{P} 50 \mathrm{rd}$, and (F) P50 BL/6. The negative control hybridizations, (G) P35 $r d 1$ and $(\mathrm{H}) \mathrm{P} 35 \mathrm{BL} / 6$, using a sense probe synthesized against the same region as the antisense strand, did not show detectable hybridization signals. The mutant retina has extensive loss of the photoreceptor outer nuclear layer, clearly evident in P35 and P50. ONL, outer nuclear layer; INL, inner nuclear layer; GCL, ganglion cell layer; OS, outer segments; OPL, outer plexiform layer; IPL, inner plexiform layer.
Several crystallin genes also showed expression changes during rod and cone death. For example, crystallin beta A4 was increased 4-fold in mutant P35 retinas and 2.8-fold at P14. A recent proteomics study of $r d 1$ retinas demonstrated that several $\alpha$ - and $\beta$-crystallin family members were induced in rod degeneration. ${ }^{80}$ Similarly, Jones et al. ${ }^{81}$ reported increased expression of $\alpha$-crystallin at P18 in $r d 1$ retinas, which was dis- tributed predominantly in the inner retina and possibly in ganglion cells and Müller end processes. In contrast, at P50, when the majority of cones are gone, there was more than a twofold decreased expression of crystallin beta A4 and alpha 1-crystallin.

Crystallins are the major structural proteins in the lens and are present in other tissues, including retina. ${ }^{82-84}$ The extra- 
TABLE 2. Identification of Candidate Photoreceptor Genes that Map within Retinal-Disease-Critical Regions

\begin{tabular}{|c|c|c|}
\hline Disease and Critical Region & $\begin{array}{cc}\text { Mouse } & \text { Human } \\
\text { UniGene } & \text { UniGene }\end{array}$ & Gene Name \\
\hline
\end{tabular}

CORD8 1q12-q24 recessive cone-rod dystrophy

ARMD1 1q25-q31 dominant MD, age-related

AXPC1 1q31-q32 recessive ataxia, posterior column with RP

BBS5 2q31 recessive Bardet-Biedl syndrome RP26 2q31-q33 recessive RP USH2B 3p24.2-p23 recessive Usher syndrome, type 2 ;
recessive sensorineural deafness without RP

WFS2 4q22-q24 recessive Wolfram syndrome; dominant

MCDR1 6q14-q16.2 dominant MD, North Carolina type; dominant progressive bifocal chorioretinal atrophy

LCA5 6q11-q16 recessive Leber congenital amaurosis

CYMD 7p21-p15 dominant MD, cystoid

AA 11 p 15 dominant atrophia areata; dominant chorioretinal degeneration, helicoid

VRNI 11q13 dominant neovascular inflammatory vitreoretinopathy

\section{LCA3 14q24 recessive Leber congenital amaurosis}

MRST $15 \mathrm{q} 24$ recessive retardation, spasticity, and retinal degeneration

CORD5 17p13-p12 dominant cone dystrophy, progressive; recessive cone-rod dystrophy

CACD $17 \mathrm{p} 13$ dominant central areolar choroidal dystrophy

USH1G 17q24-q25 recessive Usher syndrome

CORD1 18q21.1-q21.3 cone-rod dystrophy; deGrouchy syndrome

AIED Xp11.4-q21 Åland island eye disease

PRD Xp11.3-p11.23 retinal dysplasia, primary

OPA2 Xp11.4-p11.2 X-linked optic atrophy

RP24 Xq26-q27 X-linked RP
$\mathrm{Mm} .8$

Mm. 143819

Mm.2261

Mm.4598

Mm.29860

Mm.3137

Mm.29725

Mm.20429

Mm.3137

Mm.220950

Mm. 40678

Mm.220950

Mm.29816

Mm.33788

Mm.3420

Mm.4870

Hs.380869

Hs. 4788

Hs. 148495

Hs. 6194

Hs. 332012

Hs. 196384

Hs. 75074

Hs. 159437

Hs. 20999

Hs. 41717

Hs. 20999

Hs. 9663

Hs. 35804

Hs. 83428

Hs.12477

Mm.5135

Mm. 4870

Mm.23567

Mm.35680

Mm.20837

Hs. 301676

Hs. 12477

Hs.82226

Hs.121619

Hs. 20478

Mm.205578

Mm.32518

Mm.41781

Mm. 42240

Mm.46005

Mm. 5043

Mm.41687

Mm.25722

Mm.25722

Mm.8552

Mm.4793

Mm. 12508

Mm.30176

Mm.21841

Mm. 17537

Mm. 27372

Mm.92529

Mm.3555

Mm.1344

Mm.20873

Mm.1104

Mm.1344

Mm.1104

Mm. 27372

Mm.92529

Mm.1344

Mm.1104

Mm.28275

Hs. 41735

Hs. 1437

Hs. 2055

Hs. 3383

Hs. 4552

Hs. 765

Hs. 2055
Hs. 196384

Upstream transcription factor 1

Nicastrin

Proteasome 26S subunit

Chondroitin sulfate proteoglycan BEHAB/brevican

Immunoglobulin superfamily, member 8

Prostaglandin-endoperoxide synthase 2

Mitogen-activated protein kinase-activated protein kinase 2 Prospero-related homeobox 1

Prostaglandin-endoperoxide synthase 2

Hypothetical protein FLJ23142

Phosphodiesterase 1A, calmodulin-dependent

Hypothetical protein FLJ23142

Programmed cell death 6 interacting protein

Hect domain and RLD 3

Nuclear factor of kappa light polypeptide gene enhancer in B-cells 1 (p105)

Synaptosomal-associated protein, $91 \mathrm{kDa}$ homologue

Glutamate receptor, ionotropic, kainate 2

Synaptosomal-associated protein, $91 \mathrm{kDa}$ homologue

Glycoprotein (transmembrane) $\mathrm{nmb}$

Chromosome 11 open reading frame 15

Ceroid-lipofuscinosis, neuronal 2, late infantile (JanskyBielschowsky disease)

Hs.119257 Ems1 sequence (mammary tumor and squamous cell carcinoma-associated (p80/85 src substrate)

Hs.132004 Cardiotrophin-like cytokine

Hs.6059 EGF-containing fibulin-like extracellular matrix protein 2

Hs. 180677 Splicing factor 1

Hs.180789 S164 protein

Hs.25647 V-fos FBJ murine osteosarcoma viral oncogene homologue

Hs.351327 Hypothetical protein FLJ20452

Hs.41735 Purinergic receptor P2X, ligand-gated ion channel, 1

Purinergic receptor P2X, ligand-gated ion channel, 1

Hs.1578 Baculoviral IAP repeat-containing 5 (survivin)

Glucosidase, alpha; acid (Pompe disease, glycogen storage disease type II)

Hs.159557 Karyopherin alpha 2 (RAG cohort 1, importin alpha 1)

Hs.50151 Potassium inwardly rectifying channel, subfamily J, member 16

Hs.73965 Splicing factor, arginine/serine-rich 2

Hs.180933 CpG-binding protein

Hs.3383 Upstream regulatory element-binding protein 1

Hs. 4552 Ubiquilin 2

Hs.149155 Voltage-dependent anion channel 1

Hs.765 GATA-binding protein 1 (globin transcription factor 1)

Hs.211607 Trinucleotide repeat containing 11 (THR-associated protein, 230kDa subunit)

Hs.2055 Ubiquitin-activating enzyme E1

Hs.765 GATA-binding protein 1

Ubiquitin-activating enzyme E1

Upstream regulatory element-binding protein 1

Ubiquilin 2

GATA-binding protein 1

Ubiquitin-activating enzyme E1 (A1S9T and BN75

temperature sensitivity complementing)

Hs.146381 RNA-binding motif protein, X chromosome

Clones that map within the critical region of various human retinal diseases were identified. Shown for each disease region are the UniGene cluster ID, the mouse gene name, the corresponding human UniGene cluster ID and human gene name. The disease intervals were obtained from the RetNet database. 
lenticular function of $\alpha$-crystallins includes chaperone and antiapoptosis activities, and they play important roles in differentiation, development, and neurodegeneration. ${ }^{85-87} \beta$-Crystallins have also been reported to have chaperone activity during cellular stress, ${ }^{86,88,89}$ but their role in degenerated retina is not known. Crystallins are phosphorylated through cAMP-dependent and -independent pathways, ${ }^{90,91}$ suggesting that they interact with signaling-related proteins. $\alpha$-Crystallin inhibited oxidative stress-induced apoptosis in RPE cells in culture, ${ }^{92}$ and in a lens epithelial cell line, oxidative stressinduced apoptosis was associated with decreased $\alpha$-crystallin. ${ }^{93}$ Introduction of $\alpha$-crystallin into the lens cells prevented $\mathrm{H}_{2} \mathrm{O}_{2}$-induced apoptosis through inhibition of caspase- 3 activation. ${ }^{93}$ Based on these studies, it is possible that crystallins are involved in protecting cones from death caused by oxidative damage. This possibility clearly warrants further exploration.

\section{References}

1. Rattner A, Sun H, Nathans J. Molecular genetics of human retinal disease. Annu Rev Genet. 1999;33:89-131.

2. Rivolta C, Sharon D, DeAngelis MM, Dryja TP. Retinitis pigmentosa and allied diseases: numerous diseases, genes, and inheritance patterns. Hum Mol Genet. 2002;11:1219-1227.

3. Pacione LR, Szego MJ, Ikeda S, Nishina PM, McInnes RR. Progress toward understanding the genetic and biochemical mechanisms of inherited photoreceptor degenerations. Annu Rev Neurosci. 2003;26:657-700.

4. Mohand-Said S, Deudon-Combe A, Hicks D, et al. Normal retina releases a diffusible factor stimulating cone survival in the retinal degeneration mouse. Proc Natl Acad Sci USA. 1998;95:83578362.

5. Huang JC, Arden GB, Voaden MJ, Marshall J. Survival of cone responses in postmortem human retina. Doc Ophthalmol. 1993; 83:91-96.

6. LaVail MM, Yasumura D, Matthes MT, et al. Protection of mouse photoreceptors by survival factors in retinal degenerations. Invest Ophthalmol Vis Sci. 1998;39:592-602.

7. Mohand-Said S, Hicks D, Dreyfus H, Sahel J-A. Selective transplantation of rods delays cone loss in a retinitis pigmentosa model. Arch Opbthalmol. 2000;118:807-811.

8. Chang B, Hawes NL, Hurd RE, Davisson MT, Nusinowitz S, Heckenlively JR. Retinal degeneration mutants in the mouse. Vision Res. 2002; 42:517-525.

9. Reme CE, Grimm C, Hafezi F, Marti A, Wenzel A. Apoptotic cell death in retinal degenerations. Prog Retin Eye Res. 1998;17:443464 .

10. McLaughlin ME, Sandberg MA, Berson EL, Dryja TP. Recessive mutations in the gene encoding the beta-subunit of rod phosphodiesterase in patients with retinitis pigmentosa. Nat Genet. 1993; 4:130-134.

11. Lolley RN, Farber DB, Rayborn ME, Hollyfield JG. Cyclic GMP accumulation causes degeneration of photoreceptor cells: simulation of an inherited disease. Science. 1977;196:664-666.

12. Farber DB. From mice to men: the cyclic GMP phosphodiesterase gene in vision and disease. The Proctor Lecture. Invest Opbthalmol Vis Sci. 1995;36:263-275.

13. Jones BW, Watt $\mathrm{CB}$, Frederick JM, et al. Retinal remodeling triggered by photoreceptor degenerations. J Comp Neurol. 2003;464: $1-16$.

14. Peng YW, Hao Y, Petters RM, Wong F. Ectopic synaptogenesis in the mammalian retina caused by rod photoreceptor-specific mutations. Nat Neurosci. 2000;3:1121-1127.

15. Strettoi E, Porciatti V, Falsini B, Pignatelli V, Rossi C. Morphological and functional abnormalities in the inner retina of the $\mathrm{rd} / \mathrm{rd}$ mouse. J Neurosci. 2002;22:5492-5504.

16. Chaum E. Retinal neuroprotection by growth factors: a mechanistic perspective. J Cell Biochem. 2003;88:57-75.

17. Adler R. Trophic interactions in retina development and in retinal degenerations: in vivo and in vitro studies. In: Adler R, Farber D, eds. The Retina: A Model for Cell Biology. Vol 1. Orlando, FL: Academic Press; 1986:112-150.

18. Harada T, Harada C, Nakayama N, et al. Modification of glialneuronal cell interactions prevents photoreceptor apoptosis during light-induced retinal degeneration. Neuron. 2000;26:533-541.

19. Wahlin KJ, Campochiaro PA, Zack DJ, Adler R. Neurotrophic factors cause activation of intracellular signaling pathways in Müller cells and other cells of the inner retina, but not photoreceptors. Invest Opbthalmol Vis Sci. 2000;41:927-936.

20. Thanos S, Richter W, Thiel H-J. The protective role of microgliainhibitory factor in the retina suffering of hereditary photoreceptor degeneration. In: Pleyer U, Schmidt K, Thiel HJ, eds. Cell and Tissue Protection in Ophthalmology. Stuttgart, Germany: Hippokrates Verlag; 1995:195-205.

21. Swaroop A, Zack DJ. Transcriptome analysis of the retina. Genome Biol. 2002;3:REVIEWS1022.

22. Wilson AS, Hobbs BG, Speed TP, Rakoczy PE. The microarray: potential applications for ophthalmic research. Mol Vis. 2002;8: $259-270$.

23. Sinha S, Sharma A, Agarwal N, Swaroop A, Yang-Feng TL. Expression profile and chromosomal location of cDNA clones, identified from an enriched adult retina library. Invest Ophthalmol Vis Sci. 2000;41:24-28.

24. Wistow G, Bernstein SL, Wyatt MK, et al. Expressed sequence tag analysis of human retina for the NEIBank Project: retbindin, an abundant, novel retinal cDNA and alternative splicing of other retina-preferred gene transcripts. Mol Vis. 2002;8:196-204.

25. Katsanis N, Worley KC, Gonzalez G, Ansley SJ, Lupski JR. A computational/functional genomics approach for the enrichment of the retinal transcriptome and the identification of positional candidate retinopathy genes. Proc Natl Acad Sci USA. 2002;99: 14326-14331.

26. Blackshaw S, Fraioli RE, Furukawa T, Cepko CL. Comprehensive analysis of photoreceptor gene expression and the identification of candidate retinal disease genes. Cell. 2001;107:579-589.

27. Jun AS, Liu SH, Koo EH, Do DV, Stark WJ, Gottsch JD. Microarray analysis of gene expression in human donor corneas. Arch Ophthalmol. 2001;119:1629-1634.

28. Buraczynska M, Mears AJ, Zareparsi S, et al. Gene expression profile of native human retinal pigment epithelium. Invest $O p h$ thalmol Vis Sci. 2002;43:603-607.

29. Farjo R, Yu J, Othman MI, et al. Mouse eye gene microarrays for investigating ocular development and disease. Vision Res. 2002; 42:463-470.

30. Jones SE, Jomary C, Grist J, Stewart HJ, Neal MJ. Identification by array screening of altered $\mathrm{nm} 23-\mathrm{M} 2 / \mathrm{PuF}$ mRNA expression in mouse retinal degeneration. Mol Cell Biol Res Commun. 2000;4: $20-25$.

31. Jones SE, Jomary C, Grist J, Stewart HJ, Neal MJ. Modulated expression of secreted frizzled-related proteins in human retinal degeneration. Neuroreport. 2000;11:3963-3967.

32. Jones SE, Jomary C, Grist J, Stewart HJ, Neal MJ. Altered expression of secreted frizzled-related protein-2 in retinitis pigmentosa retinas. Invest Ophthalmol Vis Sci. 2000;41:1297-1301.

33. Bowne SJ, Sullivan LS, Blanton SH, et al. Mutations in the inosine monophosphate dehydrogenase 1 gene (IMPDH1) cause the RP10 form of autosomal dominant retinitis pigmentosa. Hum Mol Genet. 2002; 11:559-568.

34. Kennan A, Aherne A, Palfi A, et al. Identification of an IMPDH1 mutation in autosomal dominant retinitis pigmentosa (RP10) revealed following comparative microarray analysis of transcripts derived from retinas of wild-type and Rho(-/-) mice. $\mathrm{Hum} \mathrm{Mol}$ Genet. 2002;11:547-557.

35. Hackam AS, Qian J, Liu D, et al. Comparative gene expression analysis of murine retina and brain. $\mathrm{Mol}$ Vis. In press.

36. Altschul SF, Gish W, Miller W, Myers EW, Lipman DJ. Basic local alignment search tool. J Mol Biol. 1990;215:403-410

37. Diehn M, Sherlock G, Binkley G, et al. SOURCE: a unified genomic resource of functional annotations, ontologies, and gene expression data. Nucleic Acids Res. 2003;31:219-223.

38. Ashburner M, Ball CA, Blake JA, et al. Gene ontology: tool for the unification of biology. The Gene Ontology Consortium. Nat Genet. 2000;25:25-29. 
39. Danciger M, Kozak CA, Li T, Applebury ML, Farber DB. Genetic mapping demonstrates that the alpha-subunit of retinal cGMPphosphodiesterase is not the site of the rd mutation. Exp Eye Res. 1990;51:185-189.

40. Hegde P, Qi R, Abernathy $\mathrm{K}$, et al. A concise guide to cDNA microarray analysis. Biotechniques. 2000;29:548-550.

41. Chowers I, Gunatilaka TL, Farkas RH, et al. Identification of novel retina-enriched genes using a custom human retina cDNA microarray. Invest Ophthalmol Vis Sci. 2004;44:3732-3741.

42. Dudoit S, Yang YH. Bioconductor R packages for exploratory analysis and normalization of cDNA microarray data. In: Parmigiani G, Garrett ES, Irizarry RA, Zeger SL, eds. The Analysis of Gene Expression Data: Methods and Software. New York: Springer; 2003:73-101.

43. Tusher VG, Tibshirani R, Chu G. Significance analysis of microarrays applied to the ionizing radiation response. Proc Natl Acad Sci USA. 2001;98:5116-5121.

44. Fienberg SE. The Analysis of Cross-classified Categorical Data. 2nd ed. Cambridge, MA: MIT Press; 1980.

45. Simpson DA, Feeney S, Boyle C, Stitt AW. Retinal VEGF mRNA measured by SYBR green I fluorescence: a versatile approach to quantitative PCR. Mol Vis. 2000;6:178-183.

46. Hackam AS, Bradford RL, Bakhru RN, et al. Gene discovery in the embryonic chick retina. Mol Vis. 2003;9:262-276.

47. Yuen T, Wurmbach E, Pfeffer RL, Ebersole BJ, Sealfon SC. Accuracy and calibration of commercial oligonucleotide and custom cDNA microarrays. Nucleic Acids Res. 2002;30:E48.

48. Ramakrishnan R, Dorris D, Lublinsky A, et al. An assessment of Motorola CodeLink microarray performance for gene expression profiling applications. Nucleic Acids Res. 2002;30:E30.

49. Livesey FJ, Furukawa T, Steffen MA, Church GM, Cepko CL. Microarray analysis of the transcriptional network controlled by the photoreceptor homeobox gene Crx. Curr Biol. 2000;10:301-310.

50. Krupnik VE, Sharp JD, Jiang C, et al. Functional and structural diversity of the human Dickkopf gene family. Gene. 1999;238: 301-313.

51. Nozaki I, Tsuji T, Iijima O, et al. Reduced expression of REIC/Dkk-3 gene in non-small cell lung cancer. Int J Oncol. 2001;19:117-121.

52. Tsuji T, Nozaki I, Miyazaki M, et al. Antiproliferative activity of REIC/Dkk-3 and its significant down-regulation in non-small-cell lung carcinomas. Biochem Biophys Res Commun. 2001;289:257263.

53. Caricasole A, Ferraro T, Iacovelli L, et al. Functional characterization of WNT7A signalling in PC12 cells: interaction with a FZD5/ LRP6 receptor complex and modulation by DKK proteins. $J$ Biol Chem. 2003;278:37024-37031.

54. Caricasole A, Ferraro T, Iacovelli L, et al. Functional characterization of WNT7A signaling in PC12 cells: interaction with A FZD5 $\mathrm{x}$ LRP6 receptor complex and modulation by Dickkopf proteins. J Biol Chem. 2003;278:37024-37031.

55. Brott BK, Sokol SY. Regulation of Wnt/LRP signaling by distinct domains of Dickkopf proteins. Mol Cell Biol. 2002;22:6100 - 6110.

56. Mao B, Wu W, Li Y, et al. LDL-receptor-related protein 6 is a receptor for Dickkopf proteins. Nature. 2001;411:321-325.

57. Mao B, Wu W, Davidson G, et al. Kremen proteins are Dickkopf receptors that regulate Wnt/beta-catenin signalling. Nature. 2002; 417:664-667.

58. Jin EJ, Burrus LW, Erickson CA. The expression patterns of Wnts and their antagonists during avian eye development. Mech Dev. 2002;116:173-176.

59. Monaghan AP, Kioschis $\mathrm{P}, \mathrm{Wu}$ W, et al. Dickkopf genes are coordinately expressed in mesodermal lineages. Mech Dev. 1999;87: 45-56.

60. Carter-Dawson LD, LaVail MM, Sidman R. Differential effect of the rd mutation on rods and cones in the mouse retina. Invest Ophthalmol Vis Sci. 1978;17:489-498.

61. Ogilvie JM, Tenkova T, Lett JM, Speck J, Landgraf M, Silverman MS. Age-related distribution of cones and ON-bipolar cells in the rd mouse retina. Curr Eye Res. 1997;16:244-251.

62. Jimenez AJ, Garcia-Fernandez JM, Gonzalez B, Foster RG. The spatio-temporal pattern of photoreceptor degeneration in the aged rd/rd mouse retina. Cell Tissue Res. 1996;284:193-202.
63. Wong CM, Zhou Y, Ng RW, Kung Hf HF, Jin DY. Cooperation of yeast peroxiredoxins Tsa1p and Tsa2p in the cellular defense against oxidative and nitrosative stress. J Biol Chem. 2002;277: 5385-5394.

64. Chu FF, Esworthy RS. The expression of an intestinal form of glutathione peroxidase (GSHPx-GI) in rat intestinal epithelium. Arch Biochem Biophys. 1995;323:288-294.

65. Mackness MI, Arrol S, Abbott C, Durrington PN. Protection of low-density lipoprotein against oxidative modification by highdensity lipoprotein associated paraoxonase. Atherosclerosis. 1993; 104:129-135.

66. Yamada H, Yamada E, Ando A, et al. Fibroblast growth factor-2 decreases hyperoxia-induced photoreceptor cell death in mice. Am J Patbol. 2001;159:1113-1120.

67. Okoye G, Zimmer J, Sung J, et al. Increased expression of brainderived neurotrophic factor preserves retinal function and slows cell death from rhodopsin mutation or oxidative damage. $J \mathrm{Neu}$ rosci. 2003;23:4164- 4172 .

68. Robitaille J, MacDonald ML, Kaykas A, et al. Mutant frizzled-4 disrupts retinal angiogenesis in familial exudative vitreoretinopathy. Nat Genet. 2002;32:326-330.

69. Chen S, Guttridge DC, You Z, et al. Wnt-1 signaling inhibits apoptosis by activating beta-catenin/T cell factor-mediated transcription. J Cell Biol. 2001;152:87-96.

70. Shou J, Ali-Osman F, Multani AS, Pathak S, Fedi P, Srivenugopal KS. Human Dkk-1, a gene encoding a Wnt antagonist, responds to DNA damage and its overexpression sensitizes brain tumor cells to apoptosis following alkylation damage of DNA. Oncogene. 2002; 21:878-889.

71. Mukobata S, Hibino T, Sugiyama A, et al. M6a acts as a nerve growth factor-gated $\mathrm{Ca}(2+)$ channel in neuronal differentiation. Biochem Biophys Res Commun. 2002;297:722-728.

72. Hernandez-Sanchez C, Lopez-Carranza A, Alarcon C, de La Rosa EJ, de Pablo F. Autocrine/paracrine role of insulin-related growth factors in neurogenesis: local expression and effects on cell proliferation and differentiation in retina. Proc Natl Acad Sci USA. 1995;92:9834-9838.

73. Ekstrom P, Sanyal S, Narfstrom K, Chader GJ, van Veen T. Accumulation of glial fibrillary acidic protein in Muller radial glia during retinal degeneration. Invest Ophthalmol Vis Sci. 1988;29:13631371.

74. Rich KA, Zhan Y, Blanks JC. Aberrant expression of c-Fos accompanies photoreceptor cell death in the rd mouse. $J$ Neurobiol. 1997;32:593-612.

75. Lewis GP, Matsumoto B, Fisher SK. Changes in the organization and expression of cytoskeletal proteins during retinal degeneration induced by retinal detachment. Invest Ophthalmol Vis Sci. 1995;36:2404-2416.

76. Choi J, Conrad CC, Dai R, et al. Vitamin E prevents oxidation of antiapoptotic proteins in neuronal cells. Proteomics. 2003;3:7377.

77. Silos-Santiago I, Yeh HJ, Gurrieri MA, et al. Localization of pleiotrophin and its mRNA in subpopulations of neurons and their corresponding axonal tracts suggests important roles in neural-glial interactions during development and in maturity. $J$ Neurobiol. 1996;31:283-296.

78. Tanaka M, Marunouchi T, Sawada M. Expression of Ly-6C on microglia in the developing and adult mouse brain. Neurosci Lett. 1997;239:17-20.

79. Harada T, Harada C, Kohsaka S, et al. Microglia-Muller glia cell interactions control neurotrophic factor production during lightinduced retinal degeneration. J Neurosci. 2002;22:9228-9236.

80. Cavusoglu N, Thierse D, Mohand-Said S, et al. Differential proteomic analysis of the mouse retina: the induction of crystallin proteins by retinal degeneration in the rd 1 mouse. Mol Cell Proteom. 2003;2:494-505.

81. Jones SE, Jomary C, Grist J, Thomas MR, Neal MJ. Expression of alphaB-crystallin in a mouse model of inherited retinal degeneration. Neuroreport. 1998;9:4161-4165.

82. Magabo KS, Horwitz J, Piatigorsky J, Kantorow M. Expression of $\beta \mathrm{B}(2)$-crystallin mRNA and protein in retina, brain, and testis. Invest Ophthalmol Vis Sci. 2000;41:3056-3060. 
83. Bhat SP, Nagineni CN. alpha B subunit of lens-specific protein alpha-crystallin is present in other ocular and non-ocular tissues. Biochem Biophys Res Commun. 1989;158:319-325.

84. Xi J, Farjo R, Yoshida S, Kern TS, Swaroop A, Andley UP. A comprehensive analysis of the expression of crystallins in mouse retina. Mol Vis. 2003;9:410-419.

85. Narberhaus F. Alpha-crystallin-type heat shock proteins: socializing minichaperones in the context of a multichaperone network. Microbiol Mol Biol Rev. 2002;66:64-93.

86. Bhat SP. Crystallins, genes and cataract. Prog Drug Res. 2003;60: 205-262.

87. Kamradt MC, Chen F, Cryns VL. The small heat shock protein alpha B-crystallin negatively regulates cytochrome c- and caspase8-dependent activation of caspase-3 by inhibiting its autoproteolytic maturation. J Biol Chem. 2001;276:16059-16063.

88. Senthilkumar R, Chaerkady R, Sharma KK. Identification and properties of anti-chaperone-like peptides derived from oxidized bovine lens betaL-crystallins. J Biol Chem. 2002;277:39136-39143.
89. Wiesmann KE, Coop A, Goode D, Hepburne-Scott HW, Crabbe MJ. Effect of mutations of murine lens alphaB crystallin on transfected neural cell viability and cellular translocation in response to stress. FEBS Lett. 1998;438:25-31.

90. Kantorow M, Piatigorsky J. Phosphorylations of alpha A- and alpha B-crystallin. Int J Biol Macromol. 1998;22:307-314.

91. Koteiche HA, McHaourab HS. Mechanism of chaperone function in small heat-shock proteins: phosphorylation-induced activation of two-mode binding in alphaB-crystallin. J Biol Chem. 2003;278: 10361-10367.

92. Alge CS, Priglinger SG, Neubauer AS, et al. Retinal pigment epithelium is protected against apoptosis by alphaB-crystallin. Invest Ophthalmol Vis Sci. 2002;43:3575-3582.

93. Mao YW, Xiang H, Wang J, Korsmeyer S, Reddan J, Li DW. Human bcl-2 gene attenuates the ability of rabbit lens epithelial cells against $\mathrm{H} 2 \mathrm{O} 2$-induced apoptosis through down-regulation of the alpha B-crystallin gene. J Biol Cbem. 2001;276:4343543445 . 